\title{
Editorial: Pigs crying, silent fish and other stories about animal welfare assessment
}

\author{
I. Veissier ${ }^{1,2 \dagger}$, H. Spoolder ${ }^{3}$, J. Rushen ${ }^{4}$ and L. Mounier ${ }^{2,1}$
}

\begin{abstract}
${ }^{1}$ INRA, UMR1213 Herbivores, F-63122 Saint-Genès-Champanelle, France; ${ }^{2}$ Université de Lyon, VetAgro Sup, UMR1213 Herbivores, F-69280 Marcy I'Etoile, France; ${ }^{3}$ WUR Livestock Research, PO Box 338, 6700 AH Wageningen, The Netherlands; ${ }^{4}$ UBC Dairy Education and Research Centre, University of British Columbia, Box 2026947 Highway 7, Agassiz, BC, Canada, VOM 1A0
\end{abstract}

The study of animal welfare is now recognised as a scientific subject on its own, emerging from the combination of various disciplines and aiming to address the growing societal and political concern for the protection of animals (Veissier and Miele, 2014). To advance our knowledge of animal welfare and to operationalise it in every day practice it is essential that we know how to assess it in a consistent, feasible and valid way. This special topic of the journal Animal presents recent advances in the assessment of animal welfare and the benefits for animals and stakeholders. The manuscripts come from a selection of presentations at the WAFL (Welfare Assessment at Farm and Group Level) Conference held in September 2014 (Clermont-Ferrand, France).

The welfare of animals is a multidimensional concept that embraces - among other things - their health, emotions, and behavioural and physiological needs. Currently, many protocols for the assessment of all dimensions of animal welfare require a full day visit on a farm (e.g. Welfare Quality ${ }^{\circledR}$, 2009a, 2009b and 2009c), which for commercial purposes is too much. This puts constraints on the practical application of indicators, as they need to be cheap and easy to measure (e.g. not requiring animal handling), and at the same time relevant, sensible and reliable. Innovative approaches are presented in this special section. First, Telkänranta et al. propose a novel approach looking at tears in pigs, and more specifically tear staining (Telkänranta et al., 2016). Interestingly enough, their findings suggest that pigs 'cry' more when they are injured (bitten tails or ears) and when they are reared in a poor environment. Second, Brenninkmeyer et al. observe that integument alterations on a cow's body are related to each other: a cow injured on a specific body segment has more chance to be injured on another specific segment due to the segments being in contact with cubicle partitions during movements of the cows (Brenninkmeyer et al., 2016). This observation allows the authors to propose clusters of body segments that are prone to the same type of injuries, even when these segments are not necessarily close

\footnotetext{
${ }^{\dagger}$ E-mail: isabelle.veissier@clermont.inra.fr
}

to each other. Grouping injuries into clusters may also reduce the time needed to assess injuries and allow for a more accurate diagnosis of the causes of integument alterations. Third, Heath et al. propose an elegant way to reduce the number of observations on animals by adjusting the sample size (of animal observed) according to the prevalence of a disorder (Heath et al., 2016). Thanks to sequential sampling, the prevalence is estimated on the basis of the first observations in a series, and the sampling can be stopped early depending on how many observations are necessary to correctly detect the prevalence. This approach was successfully applied to estimate the proportion of lame cows in a herd. These three options offer possibilities to facilitate the practical assessment of animal welfare.

Before slaughter, animals may be subjected to various stressors such as long distance transport, mixing with other animals, poor handling, long periods of fasting, etc. Gallo and Huertas describe the present situation in South America based on their assessment of welfare and call for better training of handlers in order to reduce injuries and improve the welfare of animals to be slaughtered (Gallo and Huertas, 2016). Welfare assessment techniques are also relevant at the abattoir. Pre-slaughter stunning is compulsory in many countries and aims at making the animal unconscious before it is bled. However, stunning is not always carried out effectively, and therefore it is essential to check that an animal is properly stunned before bleeding it. Parotat et al. propose to spray hot water on the nose of a stunned pig and to score its movements to rapidly check that the animal is unconscious (Parotat et al., 2016). However, it is also relevant to note that immobilisation does not equal unconsciousness. Indeed, Gräns et al. found that $\mathrm{CO}_{2}$-stunned fish are hyperactive until they fall unconscious, whereas electrically stunned fishes immediately immobilise (Gräns et al., 2016). However, the blood cortisol levels of the latter are much higher, suggesting a higher level of stress. Here again, it is necessary to design methods to stun animals effectively and to check the response of the animals using indicators designed to assess the welfare state of the animal. 
Health plans to eradicate or diminish the occurrence of diseases that affect farm animal productivity are increasingly used. However, the impact of such plans on animal welfare is rarely questioned. Muri et al. report the experience gained from a Norwegian plan to eradicate arthritis encephalitis, caseous lymphadenitis and paratuberculosis in goats. Not only did these diseases regress, but implementing the plan also improved the overall welfare of animals, as shown by animals being less fearful of humans (Muri et al., 2016). This suggests that win-win solutions can be found to improve the various dimensions of welfare, herd health and the human-animal relationship.

Two papers are focussed on the fact that scientific knowledge is not sufficient to put in place appropriate welfare plans. Butterworth et al. take the example of the European Union (EU) Broiler Directive (2007/43/EC) that introduced animal-based indicators of welfare, such indicators having been scientifically validated (Butterworth et al., 2016). They show that EU member states may use different methods to record these indicators. More importantly, exchanges of technical information between member states may improve the implementation of the Directive. Nevertheless, although welfare problems are often easily recognised, it is not always easy to find remedial solutions accepted by stakeholders. As Weary et al. discuss in their conference contribution, this calls for bridging animal and social sciences to adequately address welfare problems in practice (Weary et al., 2016).

The WAFL conferences offer such opportunities of cross-fertilisation between disciplines. The next WAFL will be held in The Netherlands in 2017.

\section{References}

Brenninkmeyer C, Dippel S, Brinkmann J, March S, Winckler C and Knierim U 2016. Investigating integument alterations in cubicle housed dairy cows: which types and locations can be combined? Animal 10, 342-348.

Butterworth A, de Jong IC, Keppler C, Knierima U, Stadig L and Lambton S 2016. What is being measured, and by whom? Facilitation of communication on technical measures amongst competent authorities in the implementation of the European Union Broiler Directive (2007/43/EC). Animal 10, 302-308.

Gallo CB and Huertas SM 2016. Main animal welfare problems in ruminant livestock during preslaughter operations: a South American view. Animal 10, 357-364.

Gräns A, Niklasson L, Sandblom E, Sundell K, Algers B, Berg C, Lundh T, Axelsson M, Sundh $\mathrm{H}$ and Kiessling A 2016. Stunning fish with $\mathrm{CO}_{2}$ or electricity: contradictory results on behavioural and physiological stress responses. Animal 10, 294-301.

Heath CAE, Main DCJ, Mullan S, Haskell MJ and Browne WJ 2016. Sequential sampling: a novel method in farm animal welfare assessment. Animal 10, 349-356.

Muri K, Leine $\mathrm{N}$ and Valle PS 2016. Welfare effects of a disease eradication programme for dairy goats. Animal 10, 333-341.

Parotat S, K von Holleben, Arnold S, Troeger K and Luecker E 2016. Hot-water spraying is a sensitive test for signs of life before dressing and scalding in pig abattoirs with carbon dioxide $\left(\mathrm{CO}_{2}\right)$ stunning. Animal 10, 326-332.

Telkänranta H, Marchant-Forde JN and Valros A 2016. Tear staining in pigs: a potential tool for welfare assessment on commercial farms. Animal 10, 318-325.

Veissier I and Miele M 2014. Animal welfare: towards transdisciplinarity - the European experience. Animal Production Science 54, 1119-1129.

Weary DM, Ventura BA and von Keyserlingk MAG 2016. Societal views and animal welfare science: understanding why the modified cage may fail and other stories. Animal 10, 309-317.

Welfare Quality ${ }^{\circledR}$ 2009a. Welfare Quality ${ }^{\circledR}$ assessment protocol for cattle (fattening cattle, dairy cows, veal calves). Welfare Quality ${ }^{\circledR}$ Consortium, Lelystad, The Netherlands.

Welfare Quality ${ }^{\circledR}$ 2009b. Welfare Quality ${ }^{\circledR}$ assessment protocol for pigs (sows and piglets, growing and finishing pigs). Welfare Quality ${ }^{\circledR}$ Consortium, Lelystad, The Netherlands.

Welfare Quality ${ }^{\circledR} 2009 \mathrm{cWelfare}$ Quality ${ }^{\circledR}$ assessment protocol for poultry (broilers, laying hens). Welfare Quality ${ }^{\circledR}$ Consortium, Lelystad, The Netherlands. 